\title{
AVALIAÇÃO DO CICLO DE VIDA E CONSTRUÇÃO CIVIL: UMA REVISÃO DA LITERATURA ACERCA DA AVALIAÇÃO DE RESIDÊNCIAS UNIFAMILIARES
}

\section{LIFE CYCLE ASSESSMENT AND CIVIL CONSTRUCTION: A REVIEW OF THE LITERATURE ON THE EVALUATION OF SINGLE-FAMILY HOUSES}

\section{T. L. PILZ ${ }^{1, *}$ and M. M. C. MACENO ${ }^{1}$}

${ }^{1}$ Federal University of Paraná, Department of Production Engineering, Curitiba, Paraná, Brazil

${ }^{*}$ Corresponding author. Federal University of Paraná, Department of Production Engineering, Curitiba, Paraná, Brazil, Phone: +5547991566085

e-mail address: thaisa.pilz@gmail.com (T.L. Pilz).

\section{A R T I C L E IN F O}

Article history:

Received 2019-11-03

Accepted 2020-01-03

Available online 2020-12-20

palavras-chave

Avaliação do Ciclo de Vida

Métodos de AICV

Residências Unifamiliares

keywords

Life Cycle Assessment

LCIA methods

Single-family houses
A B S T R A C T

Environmental issues have been prominent in conferences on sustainable development. Identifying the possible environmental impacts and acting in a way to minimize them, has become a priority in organizations of different segments. The same occurs for the construction industry which is responsible for environmental impacts throughout the life cycle of its products, due to the consumption of resources and energy. In view of this, this work aimed to highlight the main subjects of the Life Cycle Assessment (LCA) phases (goal and scope definition, inventory analysis and impact assessment) to identify LCIA (Life Cycle Impact Assessment) methods applied to the evaluation of single-family houses. Through a systematic review of the literature, it was found that the main categories of impact were ozone depletion, eutrophication, acidification, climate change, resource depletion and human toxicity. In addition, methods such as ReCiPe, Eco-Indicator 99, IMPACT 2002+ and CML have been found to be most useful for evaluating buildings.

\section{R E S U M O}

Faz alguns anos que as questões ambientais vêm ocupando espaço de destaque em conferências sobre o desenvolvimento sustentável. Identificar os possíveis impactos ambientais e atuar de modo a minimizá-los, tornou-se uma das prioridades em organizações de diversos segmentos. O mesmo ocorre para a indústria da construção civil que, devido ao consumo de recursos e energia, torna-se responsável por impactos ambientais ao longo do ciclo de vida dos seus produtos. À vista disso, esse trabalho teve o objetivo de destacar os principais itens das fases da Avaliação do Ciclo de Vida (ACV) (definição do objetivo e escopo, inventário e avaliação do impacto) e identificar os métodos de AICV (Avaliação do Impacto do Ciclo de Vida) aplicados à avaliação de residências unifamiliares. Por meio de uma revisão sistemática da literatura, verificou-se que as categorias de impacto que mais se destacaram foram a depleção da camada de ozônio, eutrofização, acidificação, mudanças climáticas, esgotamento de recursos e toxicidade humana. Além disso, métodos como ReCiPe, Eco-indicator 99, IMPACT 2002 + e o CMLforam identificados como os mais adequados para a avaliação de edificações. 


\section{INTRODUÇ̃̃̃O}

Os impactos ambientais das construções residenciais variam de acordo com o tamanho, padrão, características da edificação, número de ocupantes, sistemas de construção e materiais (Evangelista et al., 2018).

Para a avaliação desses impactos, a metodologia de Avaliação do Ciclo de Vida (ACV) tem sido usada no setor da construção civil desde a década de 90 e tornou-se uma técnica de grande magnitude para a promoção de construções sustentáveis (Boonstra e Pettersen, 2003).

Conforme a NBR 14040, a ACV é definida como uma técnica de gestão ambiental que avalia de forma sistemática o desempenho ambiental do ciclo de vida de sistemas de produto (ABNT, 2009a). Por meio dessa técnica é possível identificar as atividades com maior contribuição nos impactos dentro do sistema de produto e criar estratégias para a tomada de decisões.

Para o estudo de ACV é necessário passar por 4 fases de desenvolvimento, sendo elas a definição do objetivo e escopo, a criação do inventário do ciclo de vida (ICV), o cálculo e avaliação dos impactos potenciais (AICV) e a interpretação dos resultados (ABNT, 2009b). Ambas as fases estão relacionadas entre si, para que ajustes sejam realizados durante a execução do projeto.

Entretanto, ainda que a ACV seja uma das técnicas mais completas para a avaliação dos impactos ambientais potenciais dos produtos, existem algumas limitações relativas à sua estrutura metodológica. Uma das dificuldades surge durante a disseminação da $\mathrm{ACV}$ em estudos práticos, pois critérios comuns como parâmetros de construção, transporte, consumo de água e energia, manutenção e destinação de resíduos estão em diferentes tipologias regionais (Soust-Verdaguer et. al, 2016), dificultando a transposição dos dados para o cenário que se deseja avaliar.

Outra dificuldade é relacionada à fase de AICV. Questões como a escolha, modelagem e avaliação de categorias de impacto podem introduzir subjetividades nesta fase (ABNT, 2009a), devido a disponibilidade de diversos bancos de dados para o ICV e diversos métodos de AICV. A variabilidade da nomenclatura utilizada em cada fonte impede a combinação direta de diferentes dados (Acero et al., 2015) e dificulta a conversão dos resultados do ICV em impactos ambientais e em indicadores únicos (Bovea e Gallardo, 2006). Dessa forma, quando realizada a comparação entre os resultados obtidos através de cada método de AICV, os mesmos podem apresentar variações entre os valores encontrados para cada categoria de impacto.

Portanto, para contextualizar os parâmetros determinados na ACV de construções residenciais, foi realizada uma revisão sistemática da literatura com o objetivo de destacar os principais itens das fases da ACV (definição do objetivo e escopo, ICV e AICV) e identificar os métodos de AICV mais utilizados para a avaliação de residências unifamiliares.

\section{METODOLOGIA}

A revisão sistemática da literatura é baseada na formulação adequada de uma pergunta de pesquisa e na aplicação de critérios para o rastreamento sistemático de estudos pertinentes à um determinado tema. Esta etapa é fundamental para a definição das estratégias de seleção dos estudos e identificação e análise das informações que necessitam ser coletadas (Cordeiro et al., 2007).

A condução da revisão sistemática da literatura (RSL) deste trabalho se deu através da formulação das etapas de desenvolvimento da pesquisa para a padronização da busca. Baseado no processo de seleção apresentado por Gohr et al. (2012), as respectivas etapas de pesquisa foram estruturadas para facilitar a busca por trabalhos significativos ao tema da pesquisa (Figura 1).

\begin{tabular}{|c|c|}
\hline $\begin{array}{l}2.1 \text { Delimitação } \\
\text { da pesquisa }\end{array}$ & $\begin{array}{l}\text { - Formulação do objetivo da pesquisa } \\
\text {-Definição das palavras-chave e combinações } \\
\text { - Delimitação do período de publicação (2012-2018) } \\
\text { •-Seleção das bases de dados (Science Direct e Springer Link) }\end{array}$ \\
\hline $\begin{array}{l}2.2 \text { Pesquisa e } \\
\text { seleção dos } \\
\text { estudos }\end{array}$ & $\begin{array}{l}\text { - Filtragem dos artigos por tipo (Research Articles e Review Articles) } \\
\text { - Filtragem dos artigos por relevância ao tema } \\
\text { - Filtragem por duplicidade } \\
\text { - Inclusão de artigos contidos na referências e seleção }\end{array}$ \\
\hline $\begin{array}{l}\text { 2.3 Classificação } \\
\text { geral }\end{array}$ & $\begin{array}{l}\text { - Classificação por autores, título, ano, país e periódico } \\
\text { - Análise das citações } \\
\text { - Leitura completa dos artigos selecionados } \\
\text {-Apresentação dos resultados }\end{array}$ \\
\hline
\end{tabular}

\section{Figura 1 - Etapas de Pesquisa.}

\subsection{Delimitação da pesquisa}

Consoante à necessidade de identificar artigos que apresentavam as características da ACV para a avaliação de residências e métodos de AICV adequados para a mensuração do desempenho ambiental na construção civil, foi estabelecido, inicialmente, o objetivo da pesquisa.

O objetivo da RSL consistiu na identificação de estudos de revisão e de aplicações da ACV que utilizaram métodos de AICV compatíveis às categorias de impacto existentes no processo de construção de uma casa popular. Além disso, o estudo buscou revelar informações acerca da modelagem das fases do ciclo de vida para residências unifamiliares, como o objetivo de cada estudo, objeto avaliado, unidade funcional, fluxo de referência, norma utilizada, fronteira do sistema, bases de dados e softwares escolhidos.

Para atender ao objetivo da pesquisa, além da definição das palavras-chave, delimitou-se, também, o período de publicação para os últimos 6 anos (2012-2018), para que somente estudos recentes fizessem parte da amostra final de artigos.

Uma vez que o objetivo foi encontrar estudos que realizaram a ACV de residências unifamiliares e destacassem, principalmente, a fase de construção, definiu-se para a busca as palavras-chave "avaliação do ciclo de vida ou desempenho ambiental", "processo construtivo ou sistema construtivo" e "residência unifamiliar", ambas traduzidas para o idioma inglês.

Outra delimitação estabelecida referiu-se à devida combinação das palavras-chave e suas variações, conforme requisitos exigidos nas bases de dados. Para tal, duas bases de dados, Science Direct e Springer Link, foram escolhidas devido ao acesso a journals consagrados e que não estão indexados em uma das bases, como o "The International Journal of Life Cycle Assessment" (Tabela 1). 
Tabela 1 - Parâmetros de Busca.

\begin{tabular}{lcc} 
Base de Dados & Combinações & Limites de Busca \\
Science Direct & $\begin{array}{c}\text { ("LCA" OR "life cycle assessment" OR "environmental } \\
\text { performance") AND ("building process" OR "construction } \\
\text { process" OR "constructive system") AND "Single family" }\end{array}$ & Todo o texto \\
Springer Link & 'LCA AND single-family AND (construction OR building OR & $\begin{array}{c}\text { Título, resumo, palavras- } \\
\text { chave do autor e palavras- } \\
\text { chave criadas }\end{array}$ \\
\hline
\end{tabular}

O operador booleano "AND" foi utilizado para a busca de documentos que contivessem todas as palavras-chave determinadas, e o operador "OR" para considerar as variações de cada palavra-chave. Na base de dados Science Direct, os termos foram rastreados em todo o texto do documento. Entretanto, na base Springer Link, os termos foram rastreados somente no título, resumo, palavras-chave do autor e palavraschave criadas. Além disso, devido à quantidade de variações para a palavra-chave "residência unifamiliar" no idioma inglês, foi estabelecido para a pesquisa somente o uso da palavra "unifamiliar".

\subsection{Pesquisa e seleção dos estudos}

Para a seleção dos artigos, a estratégia adotada compreendeu a busca de documentos nas bases de dados definidas na etapa anterior e a aplicação dos filtros necessários para a obtenção da amostra final de artigos (Tabela 2).

Tabela 2 - Resultados da filtragem de artigos.

\begin{tabular}{ccccccc}
\hline Base de Dados & $\begin{array}{c}\text { Resultado } \\
\text { Inicial }\end{array}$ & $\mathbf{1}^{\mathbf{0}}$ Filtro & $\mathbf{2}^{\mathbf{0}}$ Filtro & $\mathbf{3}^{\mathbf{0}}$ Filtro & $\begin{array}{c}\text { Inclusão de } \\
\text { Artigos }\end{array}$ & $\begin{array}{c}\text { Resultado } \\
\text { Final }\end{array}$ \\
Science Direct & 140 & 114 & 5 & 5 & 1 & 6 \\
Springer Link & 103 & 52 & 4 & 4 & 4 \\
Total & 243 & 166 & 9 & 9 & 10 \\
\hline
\end{tabular}

O primeiro filtro foi aplicado para a exclusão de documentos que não fossem artigos de pesquisa (Research Articles) e de revisão (Review Articles). Com um total de 166 artigos na primeira filtragem - 114 no Science Direct e 52 no Springer Link, os 77 documentos excluídos corresponderam a capítulos de livro, enciclopédias e artigos e resumos publicados em congressos.

O segundo filtro se deu por meio da avaliação do conteúdo contido nos títulos e resumos dos estudos. Além disso, com o objetivo de refinar os resultados quanto ao assunto de interesse, foi feita a análise superficial do conteúdo dos documentos que não foram excluídos apenas com a leitura do título e resumo. Nessa etapa, os critérios de exclusão aplicados aos 157 documentos foram definidos quanto à irrelevância ao tema em estudo, estudos que contivessem avaliações de outros tipos de edificações, reformas, pavimentos ou componentes isolados de uma construção e estudos que realizaram somente a Avaliação do Ciclo de Vida Energético (ACVE).
O terceiro filtro teve o objetivo de investigar se entre os 9 estudos selecionados em ambas as bases de dados, haveria algum repetido entre as bases. Verificou-se, portanto, que não ocorreu duplicidade entre as bases.

Por fim, após análise, foi observada nas referências de um dos artigos de revisão a existência de um estudo interessante para compor o quadro final de artigos, totalizando a seleção de 10 artigos e a exclusão de 233.

\subsection{Classificação geral}

Esta etapa é composta pela classificação geral dos 10 artigos selecionados e leitura integral do texto.

A relação dos artigos que serviram para fomentar as discussões propostas neste trabalho, assim como a análise das citações, conforme as bases de dados Web of Science e Scopus, está organizada na Tabela 3.

Tabela 3 - Classificação geral dos artigos e análise das citações.

\begin{tabular}{l|c|c|c}
\multicolumn{1}{c}{ Título } & Autores, ano e país & Revista & $\begin{array}{c}\text { Web of } \\
\text { science }\end{array}$ \\
$\begin{array}{l}\text { Life cycle assessment (LCA) and life cycle } \\
\text { energy analysis (LCEA) of buildings and the } \\
\text { building sector: A review }\end{array}$ & (Cabeza et al., 2014), Espanha & $\begin{array}{c}\text { Renewable and } \\
\text { Sustainable Energy } \\
\text { Reviews }\end{array}$ & 244 \\
\hline $\begin{array}{l}\text { Simplification in life cycle assessment of } \\
\text { single family houses: A review of recent } \\
\text { developments }\end{array}$ & $\begin{array}{c}\text { (Soust-Verdaguer et al., 2016), } \\
\text { Espanha }\end{array}$ & $\begin{array}{c}\text { Building and } \\
\text { Environment }\end{array}$ & 11 \\
\hline $\begin{array}{l}\text { Environmental performance analysis of } \\
\text { residential buildings in Brazil using life cycle } \\
\text { assessment (LCA) }\end{array}$ & $\begin{array}{c}\text { (Evangelista et al., 2018), } \\
\text { Brasil }\end{array}$ & $\begin{array}{c}\text { Construction and } \\
\text { Building Materials }\end{array}$ & 0 \\
\hline $\begin{array}{l}\text { Inclusion of prevention scenarios in LCA of } \\
\text { construction waste management }\end{array}$ & $\begin{array}{c}\text { (Bizocho-Tocón e Llatas, } \\
\text { 2018), Espanha }\end{array}$ & $\begin{array}{c}\text { The International } \\
\text { Journal of Life Cycle } \\
\text { Assessment }\end{array}$ & 0 \\
\hline
\end{tabular}




\begin{tabular}{|c|c|c|c|c|}
\hline $\begin{array}{l}\text { Towards guidance values for the } \\
\text { environmental performance of buildings: } \\
\text { application to the statistical analysis of } 40 \\
\text { low-energy single family houses' LCA in } \\
\text { France }\end{array}$ & $\begin{array}{c}\text { (Lasvaux et al., 2017), França e } \\
\text { Suíça }\end{array}$ & $\begin{array}{c}\text { The International } \\
\text { Journal of Life Cycle } \\
\text { Assessment }\end{array}$ & 1 & 1 \\
\hline $\begin{array}{l}\text { Environmental assessment of popular single- } \\
\text { family house construction alternatives in } \\
\text { Jordan }\end{array}$ & $\begin{array}{c}\text { (El Hanandeh, 2015), Austrália } \\
\text { e Jordânia }\end{array}$ & $\begin{array}{l}\text { Building and } \\
\text { Environment }\end{array}$ & 7 & 10 \\
\hline $\begin{array}{l}\text { Emergy-based life cycle assessment (Em- } \\
\text { LCA) of multi-unit and single-family } \\
\text { residential buildings in Canada }\end{array}$ & (Reza et al., 2014), Canadá & $\begin{array}{c}\text { International Journal of } \\
\text { Sustainable Built } \\
\text { Environment }\end{array}$ & - & 12 \\
\hline $\begin{array}{l}\text { Land use impact assessment in the } \\
\text { construction sector: an analysis of LCIA } \\
\text { models and case study application }\end{array}$ & $\begin{array}{l}\text { (Allacker et al., 2014), Itália, } \\
\text { Bélgica e Suécia }\end{array}$ & $\begin{array}{c}\text { The International } \\
\text { Journal of Life Cycle } \\
\text { Assessment }\end{array}$ & 7 & 8 \\
\hline $\begin{array}{l}\text { Analysis of } \mathrm{CO} 2 \text { emissions in the } \\
\text { construction phase of single-family detached } \\
\text { houses }\end{array}$ & $\begin{array}{c}\text { (Pacheco-Torres et al., 2014), } \\
\text { Espanha }\end{array}$ & $\begin{array}{l}\text { Sustainable Cities and } \\
\text { Society }\end{array}$ & 9 & 11 \\
\hline $\begin{array}{l}\text { Life cycle assessment of a single-family } \\
\text { residential building in Canada: A case study }\end{array}$ & $\begin{array}{l}\text { (Zhang et al., 2014), China e } \\
\text { Canadá }\end{array}$ & Building Simulation & 8 & 9 \\
\hline
\end{tabular}

Feita a classificação dos materiais de interesse, o tópico 3 traz as informações extraídas dos artigos de pesquisa sobre as fases da ACV de cada estudo (Tabela 4 e Tabela 5), assim como discussões a respeito dos métodos de AICV utilizados nos artigos.

\section{ACV DE CONSTRUÇÕES RESIDENCIAIS}

Como o foco do trabalho foi a investigação de estudos que elaboraram a ACV de residências unifamiliares, uma ponderação utilizada foi a seleção de estudos que abordaram a avaliação em diferentes cenários de construção do mundo. Sendo assim, os artigos de revisão não foram avaliados nesta seção, resultando na análise de 8 estudos de caso. A construção dos primeiros resultados da revisão sistemática, organizados por autores, podem ser observados conforme a Tabela 4.

Tabela 4 - Características da fase de definição do objetivo e escopo dos estudos.

\begin{tabular}{|c|c|c|c|c|c|}
\hline Referência & Objetivo & $\begin{array}{c}\text { Abordagem } \\
\text { da } \mathbf{A C V}\end{array}$ & $\begin{array}{c}\text { Objeto de } \\
\text { estudo }\end{array}$ & $\begin{array}{l}\text { Unidade } \\
\text { funcional }\end{array}$ & $\begin{array}{r}\text { Tempo } \\
\text { de vida }\end{array}$ \\
\hline $\begin{array}{l}\text { (Evangelista } \\
\text { et al., 2018), } \\
\text { Brasil }\end{array}$ & $\begin{array}{l}\text { Quantificar o desempenho ambiental de } 4 \\
\text { prédios residenciais típicos brasileiros com } \\
\text { diferentes tipologias e identificar os } \\
\text { processos e materiais que mais contribuem } \\
\text { para os impactos na fase de construção }\end{array}$ & $\begin{array}{l}\text { Berço ao } \\
\text { túmulo }\end{array}$ & $\begin{array}{c}\text { Residência } \\
\text { Multifamiliar e } \\
\text { Residência } \\
\text { Unifamiliar - } \\
\text { alto e baixo } \\
\text { padrão }\end{array}$ & $\begin{array}{l}\text { Metros } \\
\text { quadrados da } \\
\text { área total } \\
\text { construída por } \\
\text { ano }\left(\mathrm{m}^{2} / \mathrm{ano}\right)\end{array}$ & $\begin{array}{c}50 \\
\text { anos }\end{array}$ \\
\hline $\begin{array}{l}\text { (Bizocho- } \\
\text { Tocón e } \\
\text { Llatas, 2018), } \\
\text { Espanha }\end{array}$ & $\begin{array}{l}\text { Avaliar o gerenciamento de resíduos que } \\
\text { inclui atividades de prevenção (modelo } \\
\text { proposto) em todo o ciclo de vida da } \\
\text { construção }\end{array}$ & $\begin{array}{c}\text { Berço ao } \\
\text { portão }\end{array}$ & $\begin{array}{l}\text { Residência } \\
\text { Multifamiliar }\end{array}$ & $\begin{array}{l}\text { Gestão de } 784 \\
\text { toneladas de } \\
\text { resíduos em um } \\
\text { cenário sem } \\
\text { prevenção e de } \\
310 \text { ton em um } \\
\text { cenário com } \\
\text { prevenção }\end{array}$ & - \\
\hline $\begin{array}{l}\text { (Lasvaux et } \\
\text { al., 2017), } \\
\text { França e } \\
\text { Suíça }\end{array}$ & $\begin{array}{l}\text { Avaliar } 40 \text { casas individuais de baixa energia } \\
\text { para o contexto francês, para orientações } \\
\text { quanto ao consumo de energia e água, } \\
\text { emissões de gases de efeito estufa, geração de } \\
\text { resíduos, entre outros. }\end{array}$ & $\begin{array}{l}\text { Berço ao } \\
\text { túmulo }\end{array}$ & $\begin{array}{l}\text { Residência } \\
\text { Unifamiliar }\end{array}$ & $\begin{array}{l}\text { Uma casa } \\
\text { completa }\end{array}$ & $\begin{array}{c}50 \\
\text { anos }\end{array}$ \\
\hline $\begin{array}{l}\text { (El Hanandeh, } \\
\text { 2015), } \\
\text { Jordânia }\end{array}$ & $\begin{array}{l}\text { Comparar } 6 \text { residências unifamiliares que } \\
\text { utilizam blocos de concreto oco simples } \\
\text { (Econômico), blocos de concreto oco de } \\
\text { camada dupla (econômico melhorado), } \\
\text { blocos de concreto oco de camada dupla com } \\
\text { isolamento (isolamento econômico), } \\
\text { revestimento de calcário típico, parede de } \\
\text { calcário isolado e multicamada com } \\
\text { revestimento de calcário e isolamento (luxo) }\end{array}$ & $\begin{array}{l}\text { Berço ao } \\
\text { túmulo }\end{array}$ & $\begin{array}{l}\text { Residência } \\
\text { Unifamiliar }\end{array}$ & $\begin{array}{l}\text { Uma casa } \\
\text { completa }\end{array}$ & $\begin{array}{c}50 \\
\text { anos }\end{array}$ \\
\hline $\begin{array}{l}\text { (Reza et al., } \\
\text { 2014), Canadá }\end{array}$ & $\begin{array}{l}\text { Propor uma estrutura de avaliação de } \\
\text { sustentabilidade baseada na síntese }\end{array}$ & $\begin{array}{c}\text { Berço ao } \\
\text { túmulo }\end{array}$ & $\begin{array}{l}\text { Residência } \\
\text { Unifamiliar }\end{array}$ & $\begin{array}{l}\text { Um edifício } \\
\text { completo }\end{array}$ & $\begin{array}{c}60 \\
\text { anos }\end{array}$ \\
\hline
\end{tabular}




\begin{tabular}{|c|c|c|c|c|c|}
\hline & $\begin{array}{l}\text { emergética e avaliar os impactos sócios } \\
\text { econômicos de uma construção }\end{array}$ & & & & \\
\hline $\begin{array}{l}\text { (Allacker et } \\
\text { al., 2014), } \\
\text { Itália, Bélgica } \\
\text { e Suécia }\end{array}$ & $\begin{array}{l}\text { Quantificar os impactos relativos ao uso da } \\
\text { terra pela comparação de duas residências } \\
\text { unifamiliares de telhado plano na Bélgica } \\
\text { (uma de estrutura sólida e outra de estrutura } \\
\text { de madeira) e utilização de diferentes } \\
\text { métodos de AICV }\end{array}$ & $\begin{array}{l}\text { Berço ao } \\
\text { túmulo }\end{array}$ & $\begin{array}{l}\text { Residência } \\
\text { Unifamiliar }\end{array}$ & $\begin{array}{l}1 \mathrm{~m}^{2} \text { de área útil, } \\
\text { aquecida a uma } \\
\text { temperatura } \\
\text { média diária de } \\
18^{\circ} \mathrm{C} \text {, por ano }\end{array}$ & $\begin{array}{c}60 \\
\text { anos }\end{array}$ \\
\hline $\begin{array}{l}\text { (Pacheco- } \\
\text { Torres et al., } \\
\text { 2014), } \\
\text { Espanha }\end{array}$ & $\begin{array}{l}\text { Avaliar as emissões de } \mathrm{CO} 2 \text { de uma } \\
\text { residência unifamiliar na fase de construção } \\
\text { (fornecimento de matéria-prima, transporte, } \\
\text { fabricação, transporte, processo de } \\
\text { construção e instalação local) }\end{array}$ & - & $\begin{array}{l}\text { Residência } \\
\text { Unifamiliar }\end{array}$ & $\begin{array}{l}1 \text { casa } \\
\text { unifamiliar } \\
\text { típica da } \\
\text { Espanha }\end{array}$ & - \\
\hline $\begin{array}{l}\text { (Zhang et al., } \\
\text { 2014), China } \\
\text { e Canadá }\end{array}$ & $\begin{array}{l}\text { Avaliar os impactos ambientais potenciais de } \\
\text { uma residência unifamiliar (dividida por } \\
\text { cômodos) em Vancouver utilizando } 4 \\
\text { unidades funcionais }\end{array}$ & $\begin{array}{l}\text { Berço ao } \\
\text { túmulo }\end{array}$ & $\begin{array}{c}\text { Edifício de } 2 \\
\text { andares }\end{array}$ & $\begin{array}{l}\mathrm{m}^{2} \text { de área total, } \\
\mathrm{m}^{2} \text { de área por } \\
\text { cômodos ( } 7 \\
\text { cômodos), por } \\
\text { custo em dólar e } \\
\text { por ocupante (4 } \\
\text { ocupantes } \\
\text { impactam na } \\
\text { fase de uso) }\end{array}$ & $\begin{array}{c}60 \\
\text { anos }\end{array}$ \\
\hline
\end{tabular}

Nesta etapa, buscou-se identificar quais eram os objetivos dos estudos, as fronteiras de avaliação, os objetos que estavam sendo avaliados, as unidades funcionais e os tempos estimados de durabilidade das residências

Algumas delimitações foram feitas nos estudos dos autores, como por exemplo, na ACV realizada pela Evangelista et al. (2018), que considerou para ambas as avaliações residências multifamiliares e unifamiliares, que a fase de demolição possuia $100 \%$ de geração de resíduos. Como a maioria das empresas brasileiras encaminham esses materiais para aterros sanitários, a reciclagem dos resíduos gerados após a demolição não foi considerada na avaliação.

No estudo feito por Bizocho-Tocón e Llatas (2018), a ACV foi executada com o propósito de avaliar a geração de resíduos do processo de construção de uma residência multifamiliar em dois cenários - com e sem prevenção. Para a comparação entre os dois cenários, foi determinado que o ciclo de vida incluiria os processos desde a extração da matéria-prima até a finalização da construção (berço ao portão). É possível notar que a exclusão das etapas de uso e descarte, nesse caso, não interferem na avaliação, visto que o objetivo do estudo foi incluir uma proposta de melhoria durante a fase de construção e avaliar se realmente haveria a diminuição dos impactos ambientais potenciais após a ACV.

Já o estudo feito por Lasvaux et al. (2017) considerou todos os processos que envolvem o ciclo de vida de uma residência unifamiliar e avaliou diferentes sistemas construtivos para modelos de habitações na França. Por exemplo, as 40 casas individuais avaliadas no estudo estavam em conformidade com a regulação térmica francesa, que determina para o conforto térmico um intervalo de temperatura entre 19 e $27^{\circ} \mathrm{C}$ (Lasvaux et al., 2017).

O caso tratado no artigo de Pacheco-Torres et al. (2014) teve uma abordagem diferente dos demais estudos discutidos. $\mathrm{O}$ principal objetivo foi determinar a energia incorporada com seu valor equivalente em emissões de $\mathrm{CO} 2$ para cada produto utilizado na fase construtiva e durante a instalação no local de construção (Pacheco-Torres et al., 2014). Ainda que o estudo avaliasse somente um indicador, sem o uso de softwares convencionais para o cálculo dos impactos potenciais, como é feita na ACV, o artigo foi selecionado por indicar detalhadamente as fases de uma construção e analisar em produtos e equipamentos o percentual de emissões em $\mathrm{Kg}$ de $\mathrm{CO} 2$. Verificou-se que, para a casa avaliada no artigo, as etapas de fundação, estrutura e alvenaria foram responsáveis por $61,98 \%$ das emissões de $\mathrm{CO} 2$ por $\mathrm{m}^{2}$ (Pacheco-Torres et al., 2014).

Vale salientar que os estudos de ACV realizados na Europa possuem sistemas construtivos e estruturas típicas para as construções da região, e em todos os casos de residências multifamiliares e unifamiliares, estruturas adaptadas para o aquecimento e resfriamento das casas foram adicionadas às avaliações.

Além disso, para que a análise das informações dos artigos fosse mais ampla, foi observado também quais foram as bases de dados, as categorias de impactos, os métodos de AICV, os softwares e as normas empregadas nos estudos (Tabela 5).

A maior parte dos métodos utilizados nos estudos são classificados comos métodos de midpoint, com exceção dos métodos Eco-indicator 99 (endpoint), IMPACT 2002+ (endpoint) e ReCiPe (midpoint e endpoint).

Os métodos de midpoint (ponto médio) oferecem maior transparência, pois modelam os impactos orientados aos problemas em cada estágio inicial da cadeia de causa e efeito (El Hanandeh, 2015). Alguns exemplos de categorias de impacto de midpoint são a acidificação, eutrofização, depleção da camada de ozônio, ecotoxicidade, extração de minerais, ocupação da terra e emissões gerais (ar, terra e água). Por outro lado, os métodos de endpoint (ponto final) modelam os impactos de acordo com as áreas de proteção, as quais são a Saúde Humana, Qualidade do Ecossistema e o Uso de Recursos. 


\begin{tabular}{|c|c|c|c|c|c|}
\hline Referência & $\begin{array}{c}\text { Base de dados } \\
\text { para o ICV }\end{array}$ & Categorias de Impacto & $\begin{array}{c}\text { Métodos de } \\
\text { AICV }\end{array}$ & Software & Norma \\
\hline $\begin{array}{l}\text { (Evangelista } \\
\text { et al., 2018), } \\
\text { Brasil }\end{array}$ & $\begin{array}{c}\text { Ecoinvent } \\
\text { v3.011 }\end{array}$ & $\begin{array}{l}\text { Mudanças climáticas, toxicidade humana, } \\
\text { eutrofização, acidificação, depleção do } \\
\text { ozônio, formação de ozônio fotoquímico, } \\
\text { esgotamento de recursos e demanda } \\
\text { acumulada de energia }\end{array}$ & $\begin{array}{c}\text { CED v1.08 e } \\
\text { ILCD } 2011\end{array}$ & $\begin{array}{l}\text { SimaPro } \\
8.0 .2 \\
\text { (Versão } \\
\text { profissional) }\end{array}$ & $\begin{array}{l}\text { NBR ISO } \\
14040 \mathrm{e} \\
\text { ISO } 14044\end{array}$ \\
\hline $\begin{array}{l}\text { (Bizocho- } \\
\text { Tocón e } \\
\text { Llatas, 2018), } \\
\text { Espanha }\end{array}$ & Ecoinvent v2 & $\begin{array}{l}\text { Mudanças climáticas, eutrofização, } \\
\text { acidificação, depleção da camada de } \\
\text { ozônio, toxicidade humana, oxidação } \\
\text { fotoquímica }\end{array}$ & $\begin{array}{c}\text { CED e CML } \\
2001\end{array}$ & SimaPro 7.1 & $\begin{array}{l}\text { EN } 15978, \\
\text { ISO } 14040 \\
\quad \text { e ISO } \\
14044\end{array}$ \\
\hline $\begin{array}{l}\text { (Lasvaux et } \\
\text { al., 2017), } \\
\text { França e Suíça }\end{array}$ & $\begin{array}{l}\text { Ecoinvent } \\
\text { version 2, } \\
\text { INIES EPD, } \\
\text { PEP EPD }\end{array}$ & $\begin{array}{l}\text { Potencial de acidificação da terra e da } \\
\text { água, potencial de aquecimento global, } \\
\text { consumo de energia primária não } \\
\text { renovável, consumo de água fresca } \\
\text { líquida, resíduos não perigosos e inertes, } \\
\text { resíduos radioativos }\end{array}$ & $\begin{array}{c}\text { GWP e CML } \\
2001\end{array}$ & ELODIE & $\begin{array}{l}\text { NF EN } \\
15978, \text { ISO } \\
14040 \mathrm{e} \\
\text { ISO } 14044\end{array}$ \\
\hline $\begin{array}{l}\text { (El Hanandeh, } \\
\text { 2015), } \\
\text { Jordânia }\end{array}$ & ELCD 2.0 & $\begin{array}{l}\text { Depleção de água, mudanças climáticas, } \\
\text { acidificação, toxicidade humana, } \\
\text { formação de matéria particulada }\end{array}$ & $\begin{array}{c}\text { ReCiPe e } \\
\text { Ecological } \\
\text { Scarcity } 2006 \\
\end{array}$ & $\begin{array}{c}\text { OpenLCA } \\
\text { v1.4 }\end{array}$ & ISO 14040 \\
\hline $\begin{array}{l}\text { (Reza et al., } \\
\text { 2014), Canadá }\end{array}$ & Athena libraries & $\begin{array}{l}\text { Entrada de recursos (upstream impacts) } \\
\text { incluindo os recursos renováveis e não } \\
\text { renováveis, resíduos e emissões } \\
\text { (downstream impacts) e impactos } \\
\text { socioeconômicos (custos monetários, mão } \\
\text { de obra e serviços adquiridos) }\end{array}$ & $\begin{array}{c}\text { Eco-indicator } \\
99\end{array}$ & $\begin{array}{l}\text { Athena } \\
\text { Impact } \\
\text { Estimator } \\
\quad \text { for } \\
\text { Buildings }\end{array}$ & - \\
\hline $\begin{array}{l}\text { (Allacker et } \\
\text { al., 2014), } \\
\text { Itália, Bélgica } \\
\text { e Suécia }\end{array}$ & $\begin{array}{c}\text { Ecoinvent } \\
\text { version } 2.2\end{array}$ & $\begin{array}{l}\text { Aquecimento global, mudanças } \\
\text { climáticas, toxicidade humana, depleção } \\
\text { do ozônio, acidificação do solo e da água, } \\
\text { eutrofização, criação de ozônio } \\
\text { fotoquímico, ecotoxicidade de água doce }\end{array}$ & $\begin{array}{c}\text { Eco-Indicator } \\
\text { 99, ReCiPe } \\
\text { endpoint, } \\
\text { IMPACT } \\
\text { 2002+, ReCipe } \\
\text { midpoint, } \\
\text { EPS2000, } \\
\text { Swiss } \\
\text { Ecoscarcity } \\
\end{array}$ & $\begin{array}{c}\text { SimaPro } \\
2012\end{array}$ & $\begin{array}{l}\text { EN15804, } \\
\text { EN15978 }\end{array}$ \\
\hline $\begin{array}{l}\text { (Pacheco- } \\
\text { Torres et al., } \\
\text { 2014), } \\
\text { Espanha }\end{array}$ & $\begin{array}{c}\text { Não } \\
\text { especificadas }\end{array}$ & Emissões de $\mathrm{CO}_{2}$ & - & CYPE & - \\
\hline $\begin{array}{l}\text { (Zhang et al., } \\
\text { 2014), China } \\
\text { e Canadá }\end{array}$ & $\begin{array}{c}\text { Não } \\
\text { especificadas }\end{array}$ & $\begin{array}{l}\text { Consumo de combustível fóssil, } \\
\text { aquecimento global, acidificação, saúde } \\
\text { humana e efeitos respiratórios, } \\
\text { eutrofização e depleção da camada de } \\
\text { ozônio e poluição }\end{array}$ & TRACI & $\begin{array}{l}\text { OnScreen } \\
\text { Takeoff } 3.0 \\
\text { e Athena } \\
\text { Impact } \\
\text { Estimator } \\
4.2 \\
\end{array}$ & ISO 14044 \\
\hline
\end{tabular}

Nos estudos, os critérios de escolha do método foram definidos por cada autor conforme o objetivo estabelecido na primeira fase da ACV. Por exemplo, para as casas avaliadas na Jordânia, o método utilizado para categorizar os impactos ambientais foi o ReCiPe Midpoint $(H)$ e para calcular os recursos energéticos o método Ecological Scarcity 2006 (El Hanandeh, 2015). A escolha do segundo método ocorreu devido às condições climáticas e de escassez de água na Jordânia. Além disso, todas as características da região foram consideradas para auxiliar no processo de inclusão ou exclusão dos elementos avaliados na ACV e nas categorias de impacto significativas para a região.

Outro exemplo trouxe uma abordagem diferente sobre os métodos de AICV. Allacker et al. (2014) avaliaram os impactos com a aplicação de três métodos de AICV de endpoint: o Eco Indicator 99, ReCiPe e IMPACT 2002+. Os autores concluíram que o uso da terra foi identificado como um fator decisivo nos impactos ambientais potenciais de uma casa unifamiliar de madeira única e estrutura sólida e que o Eco-Indicator 99 foi o método mais abrangente para o objetivo do estudo. Ainda segundo os autores, o IMPACT 2002+ não considerou a transformação da terra e o ReCipe não diferenciou a finalidade de uso da terra (natural ou não natural).

\section{CONCLUSÃO}

Por meio da revisão sistemática da literatura foi possível destacar algumas características sobre a realização da ACV de casas. Algumas delas foram relativas às fases de (1) definição do objetivo e escopo, (2) ICV (Inventário do Ciclo de Vida) e (3) AICV (Avaliação do Impacto do Ciclo de Vida).

Na primeira fase (1), quase todos os estudos realizaram 
a ACV com uma abordagem do berço ao túmulo (cradle-tograve), considerando como unidade funcional, geralmente, uma casa completa com tempo de vida útil padrão de 50 ou 60 anos.

Na segunda fase (2), pôde-se observar que a maior parte utilizou bases de dados para a obtenção de dados dos processos, destacando-se a base ecoinvent. Outra característica verificada em todos os estudos foi a utilização de softwares como o SimaPro (em diferentes versões) para o cadastramento dos dados de inventário e cálculo das entradas e saídas dos processos.

Por último, na terceira fase (3), conforme os métodos de AICV selecionados, diversas categorias de impacto foram avaliadas. As que se destacaram foram o potencial de acidificação, eutrofização, depleção da camada de ozônio, mudanças climáticas, esgotamento de recursos e toxicidade humana. Tais categorias são coerentes para o contexto da construção civil, uma vez que ela exige grande uso de recursos e emite quantidades significativas de $\mathrm{CO} 2$ durante a fabricação de cimento e fase de construção. É possível destacar, também, que itens como o uso da terra, o consumo de água e energia, as emissões de gases e a geração de resíduos, devem ser considerados nos métodos de avaliação para a análise completa de construções residenciais.

Vale ressaltar que a escolha do método de AICV depende do objetivo do estudo e das categorias de impacto que se deseja analisar para uma localidade específica. Variações como o clima da região, normas técnicas e guias devem ser respeitados para a avaliação coerente do ciclo de vida de casas populares, pois os resultados da AICV podem não refletir os aspectos ambientais de construções executadas em outras regiões do mundo.

R E F E R E N C I A S

ACERO, A. P.; RODRÍGUEZ, C.; CIROTH, A. LCIA methods Impact assessment methods in Life Cycle Assessment and their impact categories. GreenDelta, n. February, p. 1-23, 2015.

ALLACKER, K.; SOUZA, D. M. DE; SALA, S. Land use impact assessment in the construction sector: an analysis of LCIA models and case study application. International Journal of Life Cycle Assessment, Vol. 19, n. 11, p. 1799-1809, 2014.

ASSOCIAÇÃO BRASILEIRA DE NORMAS TÉCNICAS (ABNT). NBR ISO 14040. Gestão Ambiental Avaliação do Ciclo de Vida - Princípios e Estrutura. Rio de Janeiro, 2009a.

ASSOCIAÇÃO BRASILEIRA DE NORMAS TÉCNICAS (ABNT). NBR ISO 14044. Gestão Ambiental Avaliação do Ciclo de Vida - Requisitos e orientações. Rio de Janeiro, 2009b.

BIZOCHO-TOCÓN, N.; LLATAS, C. Inclusion of prevention scenarios in LCA of construction waste management. International Journal of Life Cycle Assessment, Vol. JLCA-D-16-, n. Eurostat 2013, 2018.

BOONSTRA, C.; PETTERSEN, T. D. Tools for environmental assessment of existing buildings. Industry and Environment, Vol. 26, n. 2-3, p. 80-83, 2003.

BOVEA, M. D.; GALLARDO, A. The influence of impact assessment methods on materials selection for ecodesign. Materials and Design, Vol. 27, n. 3, p. 209-215, 2006.

CABEZA, L. F. et al. Life cycle assessment (LCA) and life cycle energy analysis (LCEA) of buildings and the building sector: A review. Renewable and Sustainable Energy Reviews, Vol. 29, p. 394-416, 2014.

CORDEIRO, A. M. et al. Revisão sistemática: uma revisão narrativa. Revista do Colégio Brasileiro de Cirurgiões, Vol. 34, n. 6, p. 428-431, 2007.

EL HANANDEH, A. Environmental assessment of popular single-family house construction alternatives in Jordan. Building and Environment, Vol. 92, p. 192-199, 2015.

EVANGELISTA, P. P. A. et al. Environmental performance analysis of residential buildings in Brazil using life cycle assessment (LCA). Construction and Building Materials, Vol. 169, p. 748-761, 2018.

GOHR, C. F. et al. Um método para a revisão sistemática da literatura em pesquisas de engenharia de produção. Encontro Nacional de Engenharia de Produção, Vol. 33, 2013.

LASVAUX, S. et al. Towards guidance values for the environmental performance of buildings: application to the statistical analysis of 40 low-energy single family houses' LCA in France. International Journal of Life Cycle Assessment, Vol. 22, n. 5, p. 657-674, 2017.

MAGALHÃES, R. F.; DANILEVICZ, Â. DE M. F.; SAURIN, T. A. Reducing construction waste: A study of urban infrastructure projects. Waste Management, Vol. 67, p. 265-277, 2017.

PACHECO-TORRES, R. et al. Analysis of CO2 emissions in the construction phase of single-family detached houses. Sustainable Cities and Society, Vol. 12, p. 63-68, 2014.

REZA, B.; SADIQ, R.; HEWAGE, K. Emergy-based life cycle assessment (Em-LCA) of multi-unit and single-family residential buildings in Canada. International Journal of Sustainable Built Environment, Vol. 3, n. 2, p. 207224, 2014.

SOUST-VERDAGUER, B.; LLATAS, C.; GARCÍAMARTÍNEZ, A. Simplification in life cycle assessment of single-family houses: A review of recent developments. Building and Environment, Vol. 103, p. 215-227, 2016.

ZHANG, W. et al. Life cycle assessment of a single-family residential building in Canada: A case study. Building Simulation, Vol. 7, n. 4, p. 429-438, 2014. 